\title{
A CRÍTICA DE BOAVENTURA DE SOUSA SANTOS À EPISTEMOLOGIA POSITIVISTA
}

José Renato de Castro Cesar*

SOUSA SANTOS, Boaventura de. Um Discurso Sobre as Ciências. São Paulo, 5ª edição. Cortez Editora, 2008. 92 p. ISBN 85-249-0952-8

\section{Introdução}

O livro "Um discurso sobre as ciências", de Boaventura de Sousa Santos (publicado originalmente em Portugal em 1987) é fruto de uma discussão acadêmica sobre o valor das ciências, apresentando uma crítica à epistemologia positivista. Trata-se, como o autor afirma, de uma versão ampliada da sua "Oração da Sapiência", proferida na "abertura solene" de suas aulas na Universidade de Coimbra em 1985/86. Sousa Santos defende uma posição antipositivista, fundamentando seu pensamento à luz dos debates acirrados que então se travavam na física e na matemática. $\mathrm{O}$ autor coloca em causa a teoria representacional da verdade e a primazia das relações causais, afirmando que todo conhecimento é socialmente construido e que o rigor das ciências tem limites que seriam inultrapassáveis e que a objetividade das ciências não implica a sua neutralidade. Boaventura descreve a crise do paradigma dominante, identificando as linhas basilares do que designa ser o paradigma emergente, atribuindo às ciências sociais (antipositivistas) uma

* Administrador. Tecnólogo em Ciências Agrárias. Mestre em Turismo e Meio Ambiente. Doutorando em Ciências Ambientais e Conservação pela UFRJ/NUPEM. 
nova centralidade, e, que a ciência, em geral, depois de ter rompido com o senso comum, deve transformar-se num novo e mais esclarecido senso comum. Sousa Santos vê na epistemologia positivista um sinal da crise final do paradigma científico dominante (oriundo da modernidade dos séculos XVI a XVIII) e identifica os traços principais de um novo paradigma que seja capaz de conferir às ciências sociais uma nova centralidade. Segundo o autor, essa sua obra, deve ser lida e compreendida em conjunção com outro livro seu: "Conhecimento prudente para uma vida decente: Um discurso sobre as ciências revisitado".

\section{Resenha Crítica}

A obra em tela é seminal. Inspiradora. O pequeno (e grande) livro de Boaventura é utilizado por vários professores de filosofia, sociologia, história etc., para fazer com que acadêmicos neófitos compreendam as mazelas do positivismo científico que assolou as universidades, a partir do Século XIX, e que no Século XX redundou em várias catástrofes ambientais, econômicas e políticas mundo afora, dando origem, inclusive, à bomba atômica e a um consumo desenfreado e sem sentido, num mundo cada vez mais desumanizado. Boaventura desenha sua tese partindo de uma releitura do pensamento das ciências ditas "modernas", que alguns historiadores definem como Ciências Iluministas, relativas ao Século das Luzes (Século XVIII), que revolucionaram o conhecimento humano sobre a Natureza, e que permitiram a criação das leis da física, através dos cálculos matemáticos, que utilizam funções complexas da mecânica, ensejando, posteriormente, os usos da energia atômica.

Através da Revolução Científica foi possível a invenção de máquinas a vapor, a utilização de condutores hidráulicos e a revolução da engenharia, que veio a mudar o mundo pela Revolução Industrial, no final do século XVIII, gerando aspiração de grandeza, de dominação do mundo natural e criando, desde então, uma sensação de arrogância do mundo europeu diante daqueles povos denominados "primitivos", desprovidos desse conhecimento científico. No entanto, Boaventura questiona o positivismo, o objetivismo e os limites das ciências físicas e matemáticas, as assim denominadas "Hard Science" - aquele corpo de ciências que considera apenas os métodos cartesianos e as metodologias quantitativas como responsáveis pelas respostas necessárias ao desenvolvimento humano, como se nenhuma outra forma de conhecimento fora delas tivesse "valor" ou pudesse determinar a "verdade". Boaventura, portanto, questiona esse "paradigma dominante" das ciências positivistas do mundo moderno do Iluminismo (que perdura até hoje), apontando seus vícios e seus erros, assinalando já a passagem das ciências para um novo paradigma mais humano, menos arrogante e mais sociológico - como um paradigma emergen- 
te. É interessante notar, que a obra de Boaventura (1985/86) é doze anos posterior à obra de Edgar Morin (Le paradigme perdu: la nature humaine, Ed. Seul, 1973), que tenta explicar a mesma crise epistemológica das ciências, propondo uma "revolução biológica" capaz de enfrentar o reducionismo e a separação Homem-Cultura; Vida-Natureza e Física-Química. Essa crise epistemológica derivada da complexidade das ciências e dos seus métodos quantitativos, é explicada por Morin, como decorrência de uma "ciência fechada em si", e que tanto Pascal como Rousseau questionaram, ao buscarem compreender a "natureza humana" pelos idos do Iluminismo dito filosófico (especialmente com os trabalhos de Francis Bacon, René Descartes, John Locke, Baruch de Spinoza, Cesare Beccaria, Voltaire, David Hume, Adam Smith, Jean-Jacques Rousseau, Immanuel Kant, Blaise Pascal, Montesquieu e outros).

\section{Recusa da absolutização da ciência moderna}

É preciso notar que Boaventura de Sousa Santos, na sua obra, segue a mesma trilha de Edgar Morin e de C. P. Snow (1957), ao questionarem o "valor" das ciências e do conhecimento humano - seja acadêmico, literário ou popular (o dito "senso comum"). Diante de um mundo cada vez mais complexo e manipulado pela engenharia e pelos interesses econômicos de uma produção industrial ilimitada de bens de consumo, e, pela crença da sociedade numa Natureza pródiga de recursos, pronta a ser explorada por quem "de ciência"; Boaventura nos questiona se esse progresso das ciências e das artes contribuirá para purificar ou para corromper os nossos costumes? E, Boaventura nos reponde, usando as palavras de Rousseau, quando este questionou "se há relação possível entre a ciência e a virtude?". Creio ser esse o aspecto central da discussão proposta por Boaventura de Sousa Santos em seu livro e que inspira outros filósofos, sociólogos e os ditos "homens de ciência" a compreenderem os aspectos insólitos do paradigma dominante. Especialmente, diante desse novo paradigma que Boaventura sugere como emergente (e que Morin propôs como sendo perdido), já que segundo Sousa Santos, "perdemos a confiança epistemológica e não sabemos mais o que abundará em meio a tanta abundância científica" (sic).

Boaventura advoga pelo fim de um ciclo hegemônico da ordem científica dominante e analisa as condições teóricas e sociológicas dessa "crise epistemológica", para especular sobre o perfil de uma nova ordem científica emergente, tentando mostrar-nos que não faz mais sentido distinguir entre ciências naturais e ciências sociais. Ele propõe que a distinção hierárquica entre conhecimento científico e conhecimento vulgar tenderá a desaparecer, e, em suas próprias palavras afirma "que a prática será o fazer e o dizer da filosofia da prática" - fato que, até o momento, não se concretizou, nem 
no âmbito das ciências naturais e muito menos nas ciências sociais, como afirmam Morin, Ehrenfeld, Luño, e Lima Vaz (só para citar alguns), porque a crise é do Homem e não das ciências. De fato, Boaventura está correto ao afirmar que a racionalidade científica dominante é totalitária e arrogante quando nega caráter racional às formas de conhecimento que não seguem seus princípios e métodos epistêmicos, tão cartesianos e quantitativos. No entanto, essa crise do homem - separado da Natureza, e que tanto incomoda às ciências sociais é, na verdade, uma crise moral e ética, derivada dos "falsos humanismos" (EHRENFELD, 1992) e de uma degeneração da mística em política, "decorrentes da deterioração semântica de alguns termos da nossa linguagem tradicional" (sic, LIMA VAZ, 2000:09) e que vão gerando novos paradigmas éticos nas ciências (SANAHUJA, 2012:31). Ao reduzir a complexidade dos fenômenos naturais (ou humanos e político-sociais), o corpo das ciências tradicionais (modernas) se apoia no determinismo mecanicista e sustenta, no plano social, o horizonte cognitivo da burguesia, tal como afirma Boaventura. O que nos parece contraditório, uma vez que fica evidente em sua tese a presença da High and Low Culture na sociedade pós-moderna ${ }^{1}$, ou seja, está subjacente na cultura ocidental, como afirma Lima Vaz (op. cit.), "uma inversão profunda da ordem que deve reinar em nossa atividade psíquica e espiritual", sobre a qual precisaremos refletir para dar conta dessa crise nas ciências.

Portanto, a proposta de Boaventura de Sousa Santos, de um paradigma emergente, não é original. Mas, recorrente dentro das ciências. E deve servir para mobilizar, como ensina Lima Vaz, a nossa mente e o nosso espírito a alcançar uma realidade transcendente e não apenas imanente. No mesmo caminho seguem Moltmann, Ratzinger, Sanahuja, Gesché e outros.

Desde os ensaios de Niels Bohr (entre 1932-1957), essa crise da epistemologia científica ficou patente no mundo pós-moderno. Mas, os físicos, matemáticos e historiadores não conseguiram explicar as causas dessas mudanças, como a conseguiram alguns filósofos e teólogos. E, quando Boaventura discorre sobre as causas (mencionando Aristóteles) não se esquece de mencionar Giambattista Vico como o responsável pela mudança de paradigma nas ciências sociais.

De fato, segundo Ratzinger (2012:44 ss), os limites da compreensão moderna da realidade estão delimitados nas formas de pensar-sentir-agir que desde a Idade Média impulsionam a sociedade atual, cujas origens transitam do historicismo ( $1^{\underline{a}}$ fase); à guinada para o pensamento técnico ( $2^{\underline{a}}$ fase); para desembocar numa teologia política ou numa "teologia da revolução" (3 $3^{a}$ fase) e que, no momento, tanto desafia o modo de ser e de crer (questões da fé) do sistema social judaico-cristão, tão questionado por Ehrenfeld e outros, quando criticam o Humanismo. Da mesma forma, Luño (1992) nos propõe questionar a ética das ciências, apontando para questões morais de suma importância, tendo em vista o avanço das ciências em campos 
considerados "sem sentido" para a concepção de mundo judaico-cristão e que, segundo Sanahuja (2012:30) estão gerando uma "reengenharia social anticristã " com apoio da UNESCO e de várias outras entidades globais. Sanahuja (2012:31ss.) propõe os novos paradigmas éticos em torno das ciências e que condicionam essa "reengenharia social anticristä" que tanto tem abalado a concepção de mundo judaico-cristão, no qual estamos inseridos. Já, Adolphe Gesché (2005:96) vai mais além desse paradigma, ao construir uma "epistemologia do excesso", ao afirmar que o ser humano necessita de uma antropologia "das finalidades" - se quiser dar-se um destino que supere as crises do que ele designa como derivada da "arrogância do positivismo". Entendo essa arrogância como o desprezo que muitos cientistas têm pela teologia e pela filosofia, desprezando a transcendência do ser presente na cultura judaico-cristã. Diante de tudo isso, a tese de Boaventura de Sousa Santos, de que estaríamos em uma fase de transição de paradigmas, nos coloca, a todos, numa incerteza quanto às possibilidades de uma ciência cada vez mais antropocêntrica e desprovida da moral judaico-cristã que fundamenta a sociedade ocidental, desde seus primórdios.

\section{Conclusão}

Entre a fé e a razão existe um vasto campo de conhecimentos que nos parecem ser, atualmente, deslocados quanto ao seu sentido e à sua teleologia. As ciências naturais e sociais (positivistas ou não) pretendem explicar os mistérios do ser, do fazer (poiésis) e das ações (práxis) do homem no mundo, mas, muitas vezes, se esquecendo dos mistérios de uma Natureza criada sem a sua participação. Fato que choca os mais céticos, sejam eles crentes ou ateus. Essa constatação mobilizou nos homens de ciência, desde tempos imemoriais, uma ânsia de participação na Criação e uma vontade de criarem e recriarem um mundo moldado, apenas, na ação humana (práxis) e que acabou por se transformar numa "culpa coletiva", segundo Carl Jung (2011), quando nos deparamos com a capacidade de destruição do Homem. E, nem a história, nem a física, nem a biologia deram conta de explicar, ainda, os mistérios mais profundos da Natureza, seja do Homem, seja do Universo; colocando a Humanidade numa constante crise moral e ética diante de saberes que podem levar à destruição total de vida no Planeta Terra. Adolphe Gesché (2005) afirma que é uma falta de "sentido" essa crise humana. Uma falta de dar sentido ao próprio destino, que vá além do "ser histórico" do homem, deixando claro que não são apenas as ciências sociais que podem dar sentido aos desejos humanos.

Assim, é preciso recolocar de pé a ordem hierárquica do conhecimento, da qual fala Boaventura. O conhecimento popular, a ciência, a filosofia e a teologia devem seguir essa ordem de acuidade, para auxiliarem às 
pessoas a descobrirem e superarem seus limites; sem o quê, a sociedade não conseguirá suplantar as crises cíclicas pelas quais se dá a vida sobre a Terra.

Outro fato importante a lembrar é que, segundo Ratzinger (opus cit.), a ciência moderna desbancou a metafísica da Idade Média, criou o antropocentrismo das ciências sociais, baseada em técnicas e tecnologias estruturalistas, mas, desprezou o conhecimento dos mistérios do Absoluto (Teologia), que se utiliza da investigação e do saber das outras formas de iluminação dos seres humanos, sejam eles crentes ou ateus, cristãos ou não.

\section{Bibliografia}

BOHR, Niels. 1995. Física Atômica e conhecimento científico. Contraponto Editora, Rio de Janeiro.

EHRENFELD, David. 1992. Arrogância do Humanismo. Editora Campus, Rio de Janeiro.

GESCHÉ, Adolphe. 2005. O Sentido. Ed. Paulinas, São Paulo.

JUNG, Carl G. 2011. Aspectos do drama contemporâneo. Editora Vozes, Petrópolis.

LUÑO, Angel Rodriguez. 1992. Etica. Le Monnier, Firenze.

MORIN, Edgar. 1974. Il paradigma perduto: che cos'ê la natura humana. Feltrinelli, Milano.

RATZINGER, Joseph. 2012. Introdução ao Cristianismo. Edições Loyola, São Paulo.

SANAHUJA, Juan Claudio. 2012. Poder Global e Religião Universal. Ed. Ecclesiae/ CEDET, Campinas.

SNOW, C. P. 1957. Two Cultures. Cambridge University Press, Cambridge.

VAZ, Henrique Cláudio de Lima. 2000. Experiência mística e filosofia na tradição ocidental. Ed. Loyola, São Paulo. 